\title{
Uma entrevista com Carlos Alberto Faraco
}

\author{
Izete Lehmkuhl Coelho | Lattes | izete.lehmkuhl.coelho@ufsc.br \\ Universidade Federal de Santa Catarina $\mid \mathrm{CNPq}$
}

Leandra Cristina de Oliveira | Lattes | leandraletras@hotmail.com Universidade Federal de Santa Catarina

\section{Introdução}

Para representar o mundo luso e brasileiro, fizemos uma entrevista com o professor e linguista Carlos Alberto Faraco, destacando suas contribuições aos estudos sobre os pronomes de tratamento no português, disponibilizadas em especial em seu texto clássico O tratamento você em português: uma abordagem histórica, publicado pela revista Fragmenta em 1996 e recentemente reeditado pela revista LaborHistórico (v. 3, n. 2, 2017). "O texto ainda respira?" Foi o que o professor respondeu ao ser interpelado pelo editor da revista LaborHistórico sobre a possibilidade de sua reedição. Segundo Nunes de Souza (2017), que escreveu o prefácio Por que reeditar (e reler) O tratamento você em português: uma abordagem histórica, "o texto respira em cada trabalho sobre formas de tratamento do português - e hoje são muitos esses trabalhos, em grande parte inspirados pelo 'sopro' do artigo editado pela primeira vez em 1996” (p. 109). A importância desse trabalho no âmbito das investigações sobre as formas e fórmulas de tratamento no português brasileiro releva-se como obra de referência a inúmeros trabalhos de teses de doutorado e dissertações de mestrado defendidos no Brasil e a artigos diversos sobre o tema, a exemplo de alguns dos textos que estão sendo disponibilizados neste volume 20, número 2 (2019) da Revista Working Papers em Linguística.

Carlos Alberto Faraco é professor titular (aposentado) da Universidade Federal do Paraná, exercendo atualmente a função de professor colaborador dessa Universidade. Fez Graduação em Letras Português/Inglês pela Pontifícia Universidade Católica do Paraná em 1972 e Mestrado em Linguística pela Universidade Estadual de Campinas em 1978. Doutorou-se em Linguística Românica pela University of Salford em 1982. Desenvolveu de 1995 a 1996 estudos de pós-doutorado em Linguística na University of California. Foi reitor da Universidade Federal do Paraná de 1990 a 1994. Em 1999 recebeu o prêmio paranaense de Ciência e Tecnologia, da Secretaria Estadual de Ciência e Tecnologia e, em 2016, o prêmio Antenor Nascentes, da Academia Brasileira de Filologia. 
Em uma rápida inspeção de sua obra já se observa o leque e o vigor de sua produção científica -- são mais de 20 livros, 36 capítulos, vários artigos publicados em revistas científicas de prestígio, inúmeras entrevistas e artigos de divulgação científica, entre outros. Eis alguns exemplos de seus livros nas diferentes áreas de atuação: História do português (2019), Para conhecer norma linguística (2017), História sociopolítica da língua portuguesa (2016), O efeito Saussure: cem anos do Curso de Linguística Geral (2016), Linguagem escrita e alfabetização (2012), Linguagem \& Diálogo: as ideias linguísticas do Círculo de Bakhtin (2009), Norma culta brasileira: desatando alguns nós (2008), Lingüística Histórica: introdução ao estudo da história das línguas (2005). Sua preocupação com o ensino de língua materna releva-se em algumas dessas obras e também na autoria de alguns livros didáticos, como Escrever na Universidade: Fundamentos (2019), Escrever na Universidade: Texto e Discurso (2019), Língua Portuguesa: prática de redação para estudantes universitários (2008), entre outros. Nessas obras uma das preocupações de Faraco foi mostrar formas linguísticas em variação que se distanciam da norma padrão.

Nesta entrevista, Faraco expõe brevemente os caminhos percorridos em sua tese de doutorado, The Imperative Sentence in Portuguese: a semantic and historical discussion (FARACO, 1982), que culminou na escrita de seu texto sobre as formas de tratamento, $O$ tratamento você em português: uma abordagem histórica. Menciona que uma frente bastante investigada por diversos pesquisadores brasileiros diz respeito à variação entre os pronomes tu e você para a expressão da segunda pessoa do singular, especialmente em contexto morfossintático de sujeito. Acrescenta também que a questão do tratamento do interlocutor está no cerne dos eventos de interlocução, uma área extremamente sensível no estabelecimento e manutenção da interlocução.

$\mathrm{O}$ resgate da história dos pronomes de tratamento em território brasileiro realizado por Faraco e a relevância desse tema para as disciplinas de Linguística Histórica, Sociolinguística e Sociolinguística Histórica oferecem ao leitor informações históricas a respeito do funcionamento do fenômeno linguístico no Brasil, trazendo hipóteses que nortearam e norteiam pesquisas desenvolvidas no país nos últimos vinte anos.

\section{Entrevista}

Coelho e Oliveira: Para começar esta entrevista, retomamos a pergunta retórica feita por Nunes de Souza (2017, p. 110) no texto Por que reeditar (e reler) O tratamento você em português: uma abordagem histórica: em sua opinião, "o que há no artigo que faz com que ele siga respirando"? 
Carlos Alberto Faraco: Avalio que ele segue respirando porque consegui, à época, fazer uma primeira sistematização da história do você. Havia análises esparsas do fenômeno, mas nenhuma sistematização. E, curiosamente, cheguei a ela por um caminho que não dizia respeito, de início, diretamente ao você. O artigo, primeiro publicado em 1996, saiu da minha tese de doutorado, defendida em 1982. O objeto da tese era, na verdade, o imperativo em português, em especial a variação entre as formas canta/cante do imperativo singular. Intuitivamente, eu observei que, na variedade curitibana, na qual o pronome de tratamento do interlocutor singular é você, havia uma variação entre os possessivos seu/ teu e entre as formas singulares do imperativo (cante/canta). Ou seja, era perceptível que havia um rearranjo de formas gramaticais: formas do sistema $t u$ coexistindo com formas do sistema você numa variedade em que não ocorre tu como pronome de tratamento. As formas do sistema tu estavam claramente desvinculadas da sua pertença original. Para tentar entender esse fenômeno, fiz, então, um estudo histórico que me levou à entrada na língua, já no período medieval tardio, das formas de tratamento que combinam com a terceira pessoa do verbo. Nesse estudo, o foco principal acabou sendo o percurso do Vossa Mercê pela sua transformação no pronome você. Foi ficando visível que essa nova configuração das formas de tratamento tinha um impacto em várias áreas da gramática, particularmente no sistema pronominal. Ao fim e ao cabo, desapareceram formas (o vós, por exemplo), surgiram e se consolidaram novas formas (o você, por exemplo), rearranjaram-se as correlações entre pronomes (o teu e o te entram na esfera do você) e sobreviveram formas de uma parte já arcaizada do sistema (o vosso, por exemplo, ainda corrente em português europeu, agora em correlação com o vocês). Cheguei, então, à sistematização que está no artigo e que acabou motivando várias pesquisas posteriores de um fenômeno que é bastante complexo e tem muitas faces a ser exploradas. A sistematização foi apenas o primeiro passo para deslindar uma série de outros aspectos envolvidos na história e no funcionamento do sistema de tratamento em português. Só acrescento, a título de informação, que foi o caso do vosso, uma espécie de fóssil vivo na língua, que me acendeu uma luz para levantar uma hipótese interpretativa da ocorrência da forma imperativa do $t u$, num sistema sem o tu e em variação com a forma imperativa de terceira pessoa relativa ao você. Defendi que houve aqui uma desvinculação da forma da sua correlação com o tu e uma especialização pragmática: ela não concorre com a forma do você, mas coexiste com ela e aparece quando se trata de reforçar a força ilocucional do ato de fala. Também essa análise do imperativo acabou motivando inúmeras outras em sociolinguística que, de novo, têm revelado a complexidade desse fenômeno no português brasileiro. Em todas essas análises, a única coisa que critico é a tendência a se classificar o canta como forma do 
indicativo. Penso que, por esse viés, se perdem aspectos fundamentais do belo fenômeno histórico que está aí exemplificado.

Coelho e Oliveira: Falamos um pouco mais sobre esse clássico texto $O$ tratamento você em português: uma abordagem histórica. Nessa obra, você contextualiza historicamente o surgimento da forma de tratamento vossa mercê no português e sua transformação no pronome você, trazendo ao leitor explicações importantes sobre a datação da nova forma, discutindo e interpretando fatos apresentados na literatura da época. Embora saibamos que a datação de novas formas na língua é suscetível de novos achados e contestações, o seu texto influenciou muitos trabalhos posteriores, inclusive o de Odete Menon, Sobre a datação de você, ocê e senhorita, publicado na revista Fórum Linguístico em 2009 (v. 6, n. 1). Fato é que ao correlacionar o papel de ascensão social que uma burguesia urbana lisboeta exerceu sobre a mudança das formas de tratamento nominais, em especial de vossa mercê, e o contexto histórico de surgimento e difusão dessas formas, esse seu texto inaugura no âmbito da Sociolinguística Variacionista o que chamamos hoje de Sociolinguística Histórica, consolidada principalmente na obra de Conde Silvestre (2007). Como foi escrever esta obra de expressiva relevância para os estudos de Sociolinguística?

Carlos Alberto Faraco: Foi uma experiência intelectual muito impactante. Fui, desde cedo, leitor e admirador do Antoine Meillet, que foi o linguista que, na virada do século XIX para o XX, mais claramente estabeleceu as bases gerais de uma linguística que integrasse fatos estruturais (puramente linguísticos) e fatos sociais. Ao reconhecer a realidade ao mesmo tempo estrutural e social da língua, Meillet introduzia não só uma dimensão sociológica no estudo da história das línguas, como também a necessidade de buscar uma investigação histórica capaz de correlacionar de forma adequada o especificamente linguístico e o especificamente social, o que ele fez, por exemplo, no estudo do vocabulário do indo-europeu. Cito aqui palavras dele (retiradas de seu livro Linguistique historique et linguistique générale. T. I [1921] Paris: Champion Editeur, 1948, p. 17) que deixam bem clara sua tese geral: "A língua é uma instituição com uma autonomia que lhe é própria; deve-se, portanto, determinar as condições gerais da mudança de um ponto de vista puramente linguístico, e este é o objeto da linguística geral; (...) Contudo, como a língua é uma instituição social, segue daí que a linguística é uma ciência social, e o único elemento variável ao qual se pode apelar para dar conta de uma mudança linguística é a mudança social, da qual as variações da língua não passam de consequências - algumas vezes imediatas e diretas, mais frequentemente mediatas e indiretas. 
Ora, quando percebi que as mudanças no sistema do tratamento em português tinham uma clara relação com mudanças sociais, senti o poder heurístico da tese do Meillet e tentei aprofundar as relações mudanças sociais/mudanças linguísticas na minha análise, sempre lembrando, porém, a observação de Meillet de que as consequências frequentemente são mediatas e indiretas (penso aqui nos impactos sobre a morfossintaxe do português a partir das mudanças no sistema de tratamento. Este diretamente relacionado a mudanças sociais e aqueles apenas mediata e indiretamente). Acabei tendo de estudar a história de Portugal na Idade Média tardia, o que me ampliou bastante os horizontes para uma história social da língua.

Coelho e Oliveira: Nas últimas décadas, as investigações sobre as formas e fórmulas de tratamento têm se ampliado e se diversificado em termos teórico-metodológicos. Podemos considerar, a título de exemplificação, os livros Formas y fórmulas de tratamiento en el mundo hispánico, organizado por Martin Hummel, Bettina Kluge y María Eugenia Vázquez Laslop (2010), e Asformas de tratamento em português e em espanhol: variação, mudança e funções conversacionais, organizado por Leticia Rebollo Couto e Célia Regina dos Santos Lopes (2011); as sessões temáticas contempladas em eventos científicos nacionais e internacionais de grande relevância, como as promovidas pela ALFAL, em Bogotá, em julho de 2016, e pela ABRALIN, em Niterói, em março de 2017; os eventos específicos sobre o tema, como as três edições do congresso Formas e fórmulas de tratamento do mundo hispânico, luso e brasileiro; e este número especial da revista Working Papers em Linguística. A que você acha que se deve a expressiva atenção dedicada a esse fenômeno linguístico?

Carlos Alberto Faraco: Penso que a questão do tratamento do interlocutor está no cerne dos eventos da interlocução. É uma área extremamente sensível no estabelecimento e manutenção da interlocução. Tem, portanto, amplo alcance nas relações sociais. Assim, além das questões linguísticas propriamente ditas, tais como a organização e a história do sistema de tratamento e a distribuição social e geográfica das formas, há outras muitas questões de natureza sociológica, antropológica e de psicologia social que, digamos assim, enredam esse grande e fascinante tema. Daí, certamente, a expressiva atenção que esse fenômeno linguístico tem merecido.

Coelho e Oliveira: Entre as investigações sobre os sistemas de tratamento de segunda pessoa no mundo luso-brasileiro, quais estudos merecem ser destacados e quais os principais desafios a serem enfrentados? 
Carlos Alberto Faraco: Entre os muitos estudos, eu destacaria os trabalhos de Odete Menon, Célia Lopes, Márcia Rumeau, Leonardo Marcotúlio e Jânia Ramos. Há também várias dissertações e teses, ainda não publicadas, que abordam a questão por diferentes olhares: sociolinguístico, dialetológico e histórico. Esse amplo conjunto nos tem dado uma boa perspectiva da complexidade do tema e, ao mesmo tempo, ampliado nosso acervo empírico. Eu diria que há muitas coisas em aberto e muitas frentes, portanto, para investigações. Precisamos preencher, com novas documentações, lacunas da história; precisamos continuar a desvelar a grande variedade geográfica e social que existe nessa área do tratamento do interlocutor singular no português brasileiro. Estamos ainda em busca de uma ampla sistematização do quadro dos pronomes no Brasil. Para isso, é importante aproximar os estudos de $t u / v o c e ̂$ com os estudos do a gente (fenômeno que também já mereceu boas análises nos trabalhos de Ana Zilles e Célia Lopes, entre outros). Por fim, acho que seria interessante refinar a história do tratamento em Portugal. Tentar esclarecer a resistência dos falantes ao você e, ao mesmo tempo, verificar se é fato que o você vem ganhando terreno por lá, como têm apontado informalmente alguns linguistas portugueses. O tema do tratamento é sem fim. No caso específico do tratamento no português brasileiro, tenho a impressão de que nenhuma outra língua românica tem um sistema tão complexo como o nosso, resultado de inúmeras vicissitudes históricas sociais e linguísticas.

Coelho e Oliveira: Seguindo nessa linha, gostaríamos que você comentasse sobre a possibilidade de o estudo da variação e mudança das formas de tratamento superarem os limites da Linguística e se expandirem a outras áreas do conhecimento e a outros campos de atuação.

Carlos Alberto Faraco: Não tenho dúvida de que o estudo da variação e da mudança das formas de tratamento precisa de uma abordagem multidisciplinar. Como disse antes, é, talvez, a área mais sensível nos eventos de interação, cheia de sutilezas. Assim, uma investigação ampla desses eventos requer informações e perspectivas teórico-metodológicas vindas de muitas áreas do conhecimento: história social, sociologia, antropologia, psicologia social. Era um pouco com essa perspectiva em mente que eu iniciava meu artigo em 1996, dizendo: "As formas de tratamento do interlocutor nas diferentes línguas naturais têm interessado particularmente a antropólogos e linguistas. Aos primeiros, interessa estudar tais formas pelo que elas podem revelar, em sua complexa diferenciação pragmática, de aspectos da cultura (crenças e valores) de determinado grupo humano". Muito a se fazer ainda nessa imensa seara. 
Coelho e Oliveira: Para finalizar esta nossa conversa, gostaríamos de nos reportar às suas últimas pesquisas relacionadas especialmente ao que você tem chamado de pedagogia da variação linguística (ZILLES, FARACO, 2015). Ao propor uma pedagogia que estimule "uma reflexão focada nas grandes questões que envolvem a variação linguística no ensino de português, sem perder de vista uma perspectiva integradora das várias dimensões desse ensino", como você encaixaria as formas e as fórmulas de tratamento no ensino de língua materna?

Carlos Alberto Faraco: A variação e a mudança continuam ainda longe das nossas práticas pedagógicas no ensino de português. Talvez essa dificuldade de desenvolver um ensino de português que incorpore, realística e honestamente, a variação e a mudança decorra do fato de que muitos segmentos da sociedade brasileira ainda demonizam a variação (justamente por estigmatizarem os falantes de variedades socialmente desprestigiadas). Esses mesmos segmentos da sociedade não dispõem de um quadro interpretativo para absorver, sem sobressaltos, a realidade mutável da língua (de qualquer língua). Estamos ainda muito longe de uma pedagogia sociolinguisticamente bem informada. Um exemplo clássico dessa situação é o estudo do sistema pronominal. As gramáticas escolares e os livros didáticos apresentam o sistema vigente 800 anos atrás. Algumas vezes aparecem, aqui e ali, algumas tímidas referências a fenômenos modernos, mas sem qualquer sistematização e enquadrados em simplificações dicotômicas do tipo fala X escrita; formal X informal. Ora, o sistema pronominal se alterou profundamente nesses oito séculos, em especial no tratamento do(s) interlocutor(es). Penso, então, que o estudo sistematizado da variação social, geográfica e estilística das formas e fórmulas de tratamento é uma das melhores portas para introduzir os alunos no tema da variação e da mudança. É um fenômeno muito concreto na vivência de qualquer falante e, por isso, permite uma abordagem que eu costumo chamar de realista e honesta da variação - uma abordagem que explore a língua como ela é efetivamente na contemporaneidade e em suas múltiplas dimensões sociais e estilísticas.

Coelho e Oliveira: Muito obrigada! 


\section{Referências}

FARACO, C. A. The Imperative Sentence in Portuguese: a semantic and historical discussion. Tese (Doutorado em Linguística). University of Salford, Salford, 1982.

FARACO, C. A. O tratamento de você em português: uma abordagem histórica. Fragmenta. Curitiba, Ed. da UFPR, no 13, p. 51-82, 1996.

FARACO, C. A. O tratamento você em português: uma abordagem histórica. LaborHistórico. Rio de Janeiro: UFRJ, vol. 3, n. 2., p. 108-113, 2017.

NUNES DE SOUZA, C. M. Por que reeditar (e reler) "O tratamento você em português: uma abordagem histórica”. LaborHistórico, vol. 3, n. 2. Rio de Janeiro: UFRJ, p. 114-134, jul/dez. 2017.

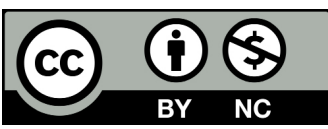

